\title{
Real-World Observational Study of Glimepiride and Metformin Fixed-Dose Combination Along With Insulin in the Management of Type 2 Diabetes Mellitus: Indian Experience
}

KM Prasanna Kumar ${ }^{1}$, Krishna Seshadri ${ }^{2}$, SR Aravind ${ }^{3}$, Prasun Deb ${ }^{4}$, KD Modi ${ }^{5}$, Raju A. Gopal ${ }^{6}$, Vijaya Kumar $\mathrm{G}^{7}$, CR Anand Moses ${ }^{8}$, Mahesh Abhyankar ${ }^{9}$, Santosh Revenkar ${ }^{9}$

1. Department of Endocrinology, Center for Diabetes and Endocrine Care, Bengaluru, IND 2. Department of Endocrinology, Apollo Speciality Hospital, Chennai, IND 3. Department of Diabetology, Diacon Hospital, Bengaluru, IND 4. Department of Endocrinology, Krishna Institute of Medical Sciences (KIMS) Hospital, Hyderabad, IND 5. Department of Endocrinology, CARE Hospital, Hyderabad, IND 6. Department of Endocrinology, Endodiab Clinic, Kozhikode, IND 7. Department of Diabetology, Diabetes Medicare Centre, Chennai, IND 8. Department of Diabetology, Moses Diabetes and Medical Centre, Chennai, IND 9. Scientific Services, USV Private Limited, Mumbai, IND

Corresponding author: Mahesh Abhyankar, drm.abhyankar@gmail.com

\section{Abstract \\ Background}

Type 2 diabetes mellitus (T2DM) is associated with a significant burden on both patients and the healthcare system. This study aimed to evaluate the demographics of patients with T2DM receiving different strengths of glimepiride and metformin combination along with insulin. This study also examined the concomitant conditions and therapies, duration of therapies, dosage titration, glycated hemoglobin (HbA1c) levels, hypoglycemic events, and weight changes during the course of therapy.

\section{Methods}

This retrospective, multicenter (347), observational study included adult patients with T2DM who received glimepiride and metformin combination along with insulin. Data related to demographic characteristics, duration of disease, co-morbidities, concomitant medications, and dosage pattern was collected from medical records authenticated by physicians during routine care.

\section{Results}

A total of 7058 patients were included in the study. The median age of included patients was 55 years and around $29 \%$ were aged $>60$ years and $60 \%$ were men. The majority of patients $(83.3 \%)$ had insulin treatment initiation after glimepiride and metformin combination while other patients $(16.7 \%)$ received glimepiride and metformin combination after insulin initiation. The mean HbA1c levels significantly decreased with a mean change of $1.33 \%$. In one-third of the patients, down-titration of the insulin dose was done, indicating the insulin-sparing effect with the addition of the glimepiride and metformin combination. The most common comorbid condition was hypertension (64.7\%). Of 3705 patients, 33.2\% patients had weight loss and $66.8 \%$ had weight gain. A total of 432 patients reported hypoglycemic events. Physician global

Review began 10/06/2020 Review ended 01/25/2021 Published 01/30/2021

\section{๑) Copyright 2021}

Prasanna Kumar et al. This is an open access article distributed under the terms of the Creative Commons Attribution License CC-BY 4.0., which permits unrestricted use, distribution, and reproduction in any medium, provided the original author and source are credited. evaluation of efficacy and tolerability showed a good to excellent on the scale (97.3\% and 96.6\%).

\section{Conclusion}

This study presented good HbA1c lowering with glimepiride and metformin combination with insulin, ensuring a positive clinical outcome. Good to excellent efficacy and tolerability were observed in patients with T2DM across the age groups, in early as well as long-standing disease.

Categories: Endocrinology/Diabetes/Metabolism, Internal Medicine, Epidemiology/Public Health Keywords: diabetes, dosage up titration, hba1c, hypoglycemic, tolerability

\section{Introduction}

Type 2 diabetes mellitus (T2DM) is predominant in the Asian population, majorly affecting young to middleaged adults, despite low body mass index (BMI) and obesity. Predictions estimated that the number of patients from Asia with diabetes would upsurge dramatically by 2025 [1]. Additionally, it is also estimated that globally 700 million adults will have diabetes by 2045 [1].

Achieving ideal glycemic control is the key goal to delay complications and advancement to T2DM. Sulfonylurea and insulin are among the commonly used drugs when the glycemic goal is not achieved by using metformin monotherapy, especially in Asian countries [2]. 
The fixed drug combination of glimepiride and metformin is highly effective in controlling blood glucose and improving glycated hemoglobin (HbA1c) levels than if used as monotherapy [3]. This combination enhances patient compliance and reduces each component drug's dosage. In addition, the therapy cost and adverse effects due to high dosage monotherapy are lowered [4].

The American Diabetes Association endorses the addition of insulin to metformin therapy and recommends consideration of the early introduction of insulin [5-6]. Nevertheless, most of the physicians are hesitant to initiate and intensify insulin therapy due to the side effects [7]. A combination of insulin with sulfonylurea works well, resulting in improved glucose levels, less weight gain, and tapered insulin dose. Similarly, it gave efficient results with metformin, showing a 10\% lowered HbA1c with $29 \%$ less insulin use and less hypoglycemia [8-11]. Instead of adding a third oral agent to the glimepiride and metformin combination, the addition of insulin resulted in lowering HbA1c levels, decreasing the need for exogenous insulin and risk of hypoglycemia and weight gain [12-13]. Moreover, studies demonstrate that early glucose control can delay macrovascular and microvascular complications and improve cardiovascular morbidity [14-15]. In Indian settings, the multiple strengths of glimepiride and metformin fixed-dose combinations are beneficial in T2DM, irrespective of age, duration of diabetes, BMI, diabetic complications, and use of concomitant medications such as insulin and statin [16].

Clinical studies have unraveled that combination therapies of oral anti-diabetic drugs and insulin offer complementary mechanisms, leading to improved therapeutic efficacy and minimal adverse reactions $[13,17-19]$. However, there are no adequate nationwide real-world data analysis in the Indian population on the use of the glimepiride and metformin combination along with insulin. The present real-world study is aimed to evaluate the demographics, treatment pattern, including duration, efficacy, various dosages of the glimepiride and metformin combination along with insulin.

\section{Materials And Methods}

\section{Study design}

This retrospective, non-randomized, non-comparative, multicenter, observational real-world study of Glycomet glimepiride-insulin (REAL GGP-INS) was conducted at 347 sites in Indian healthcare centers having medical records of adult patients with T2DM who had received treatment with glimepiride and metformin along with insulin.

Data related to demographic characteristics, duration of disease, co-morbidities, concomitant medications, and dosage patterns were collected from medical records authenticated by physicians during routine care.

\section{Study population}

Patients of either sex and age above 18 years, who have received any strength of glimepiride and metformin combination along with insulin for the treatment of T2DM and the approval of the treating physician to provide information regarding the participant's treatment, were enrolled in this study. Patients having incomplete data or any condition that, according to the discretion of the investigator, indicates that the patient is not suitable for inclusion in the study were excluded from the study.

\section{Outcome}

The outcome of this observational data analysis was the demographics of patients receiving different strengths of the glimepiride and metformin combination along with different types of insulin, concomitant conditions and therapies, duration of the glimepiride and metformin combination along with insulin therapy, up-titration and down-titration done during the course of therapy, HbA1c levels, hypoglycemic events (mild/moderate/severe/required intervention), and weight change during the course of therapy.

\section{Statistical analysis}

Statistical testing was done using appropriate statistical tests. Demographic characteristics were summarized with descriptive statistics, including median and interquartile range (IQR) for continuous variables, and frequency and percentages for categorical variables. The data from all the participating doctors were pooled for analysis and evaluable patient data were analyzed.

\section{Results}

A total of 7058 patients with T2DM were included in this retrospective observational analysis. The median age of patients was 55 years and $29.4 \%$ of the study population were in the age group of $>60$ years. The proportion of male patients (60.1\%) was higher than female patients (39.9\%).

The median duration of diabetes was significantly increased with increasing age and there was a significant difference between the age group $\geqslant 18-\leqslant 40$ years vs. $>40-\leqslant 60$ years ( 3 vs. 6 years, $p<0.001$ ), $>40-\leqslant 60$ years vs. $>60$ years ( 6 vs. 10 years, $p<0.001)$, and group $\geqslant 18-\leqslant 40$ years vs. $>60$ years ( 3 vs. 10 years, $p<0.001)$. 


\section{Cureus}

Obesity was significantly higher in patients of age group $>40-\leqslant 60$ years $(\mathrm{p}=0.026)$, a sedentary lifestyle was significantly higher in patients of age group $\geqslant 18-\leqslant 40$ and $>40-\leqslant 60$ years $(\mathrm{p}=0.001)$ while excess alcohol intake higher in patients of age group $>60$ years $(\mathrm{p}=0.002)$ and a family history of diabetes $(\mathrm{p}<0.001)$ was more common in patients of age group $\geqslant 18-\leqslant 40$ years as well as $>40-\leqslant 60$ years (Table 1 ).

\begin{tabular}{|c|c|c|c|c|c|}
\hline Characteristics & $\begin{array}{l}\text { Group } A \geq 18-\leq 40 \text { years } \\
(n=587)^{\dagger}\end{array}$ & $\begin{array}{l}\text { Group } B>40-\leq 60 \text { years } \\
(n=4242)^{\ddagger}\end{array}$ & $\begin{array}{l}\text { Group } C>60 \text { years } \\
(n=2229)^{\S}\end{array}$ & Total $(\mathrm{N}=7058)$ & P-value \\
\hline Age (years) & $38.0(35.0-39.0)$ & $52.0(48.0-56.0)$ & $66.0(63.0-71.0)$ & $55.0(48.0-62.0)$ & $<0.001^{\star, * \star *,+\star \star *}$ \\
\hline Sex, n (\%), Men & $315(53.7)$ & $2458(57.9)$ & $1470(65.9)$ & $4243(60.1)$ & $<0.001$ \\
\hline BMI $\left(\mathrm{kg} / \mathrm{m}^{2}\right)$ & {$[n=543] 25.8(23.5-28.9)$} & {$[n=3924] 26.7(24.2-29.6)$} & $\begin{array}{l}{[n=2069] 26.8(24.2-} \\
29.8)\end{array}$ & $\begin{array}{l}{[n=6536] 26.7} \\
(24.2-29.7)\end{array}$ & $\begin{array}{l}<0.001^{* * * \pi}, \\
0.254^{\star *}\end{array}$ \\
\hline $\begin{array}{l}\text { DM duration } \\
\text { (years) }\end{array}$ & {$[n=498] 3.0(2.0-5.0)$} & {$[n=3693] 6.0(3.0-9.0)$} & $\begin{array}{l}{[n=1830] 10.0(6.0-} \\
15.0)\end{array}$ & $\begin{array}{l}{[n=6021] 6.0(4.0-} \\
10.0)\end{array}$ & $<0.001^{\star, * \star *,+\star \star *}$ \\
\hline $\begin{array}{l}\text { Family history of } \\
\text { diabetes }\end{array}$ & $253(43.1)$ & $1790(42.2)$ & $743(33.3)$ & $2786(39.5)$ & $<0.001$ \\
\hline Sedentary lifestyle & $237(40.4)$ & 1719 (40.5) & 797 (35.8) & $2753(39.0)$ & 0.001 \\
\hline Obesity & $191(32.5)$ & $1617(38.1)$ & $816(36.6)$ & $2624(37.2)$ & 0.026 \\
\hline Smoking & $162(27.6)$ & $1209(28.5)$ & $685(30.7)$ & $2056(29.1)$ & 0.119 \\
\hline Emotional stress & 103 (17.5) & $873(20.6)$ & $430(19.3)$ & $1406(19.9)$ & 0.151 \\
\hline $\begin{array}{l}\text { Excess alcohol } \\
\text { intake }\end{array}$ & $86(14.7)$ & $542(12.8)$ & 354 (15.9) & $982(13.9)$ & 0.002 \\
\hline Excess salt intake & 79 (13.5) & 547 (12.9) & $322(14.4)$ & 948 (13.4) & 0.220 \\
\hline Tobacco & $39(6.6)$ & $288(6.8)$ & $184(8.3)$ & $511(7.2)$ & 0.082 \\
\hline
\end{tabular}

\section{TABLE 1: Summary of baseline characteristics according to age}

Data shown as median (IQR), unless otherwise specified. $\nmid n=587 ; \ddagger n=4242 ; \S n=2229$, unless otherwise specified. BMI, body mass index; IQR, interquartile range; DM, diabetes mellitus. * group A vs $B$; ${ }^{* \star}$ group B vs $C$; ${ }^{* \star \star}$ group A vs $C$

The majority of patients (83.3\%) had insulin treatment initiation after glimepiride and metformin combination while the other patients $(16.7 \%)$ received the glimepiride and metformin combination on top of insulin. The HbA1c level at the time of initiation of insulin was between $7.5-9 \%$ in $59.4 \%$ and $>9 \%$ in $38.9 \%$ of the patients taking the glimepiride and metformin combination while the HbA1c level was $>9 \%$ and 7.5 $9 \%$ in $50.2 \%$ and $46.8 \%$, respectively, in those who received the glimepiride and metformin combination on top of insulin (Table 2). 


\section{Cureus}

\begin{tabular}{|l|l|l|}
\hline & $\begin{array}{l}\text { Insulin treatment initiation after Glimepiride and } \\
\text { metformin combination }(\mathbf{n}=5618)^{\dagger}\end{array}$ & $\begin{array}{l}\text { Glimepiride and metformin combination on top } \\
\text { of Insulin }(\mathbf{n}=1124)^{\ddagger}\end{array}$ \\
\hline $\begin{array}{l}\text { HbA1c level at } \\
\text { initiation (\%) }\end{array}$ & {$[\mathrm{n}=5381]$} & $32(2.9)$ \\
$\leq 7.5$ & $90(1.7)$ & $505(46.8)$ \\
$>7.5-\leq 9$ & $3199(59.4)$ & $541(50.2)$ \\
$>9$ & $2092(38.9)$ & \\
\hline
\end{tabular}

\section{TABLE 2: HbA1c level at initiation}

Data shown as $n(\%) . ~ † n=5618 ; ~ \ddagger n=1124$; unless otherwise specified

The treatment pattern and frequency are depicted in Figure 1. Along with insulin, the commonest strengths used were glimepiride $2 \mathrm{mg}$ and metformin $500 \mathrm{mg}$ (32.3\%) and glimepiride $1 \mathrm{mg}$ and metformin $500 \mathrm{mg}$ (27.9\%). The twice-daily (BD) frequency was more than the once-daily (OD). Down-titration of the dose of insulin was required to be done in $34.1 \%$ of patients while up-titration was done in $65.9 \%$ of patients (Table 3).

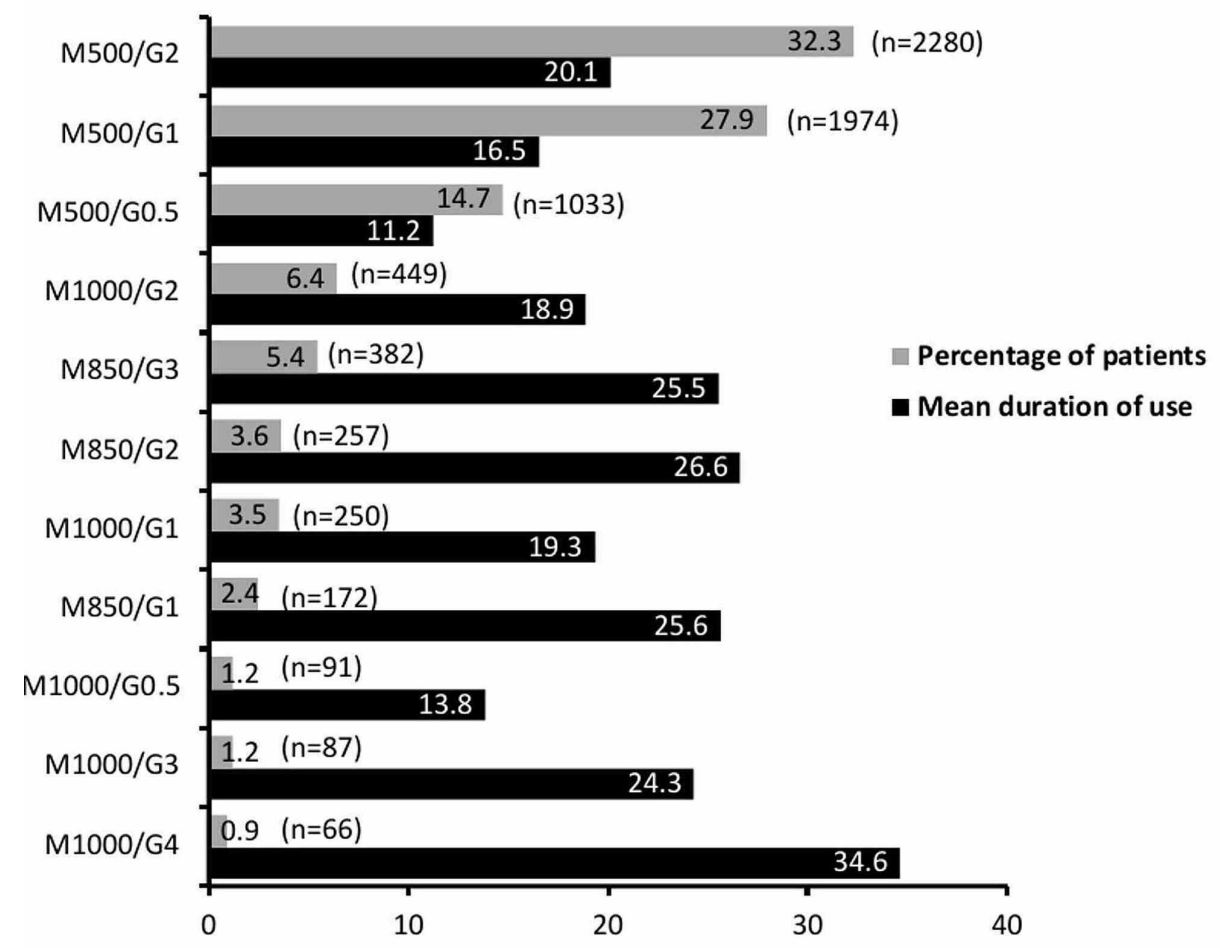

\section{FIGURE 1: Treatment pattern and duration of use}

G, glimepiride; M, metformin; compounds presented in $\mathrm{mg}$; duration of use presented in months. 


\section{Cureus}

\section{Parameters}

Concomitant diabetic medication

DPP4i

SGLT2i

AGI

TZD

GLP1 agonist

Concomitant non-diabetic medication

Antihypertensive

Statins

Drugs in neuropathic pain

Others

Dose titration of glimepiride and metformin combination

Dosage up

Dosage down

Dose titration of insulin

Dosage up

Dosage down

Patients with weight changes during the therapy

Increased weight $(\mathrm{kg})[\mathrm{n}=2474]$

$0-2$

$2-4$

$>4$

Decreased weight $(\mathrm{kg})[\mathrm{n}=1231]$

0-2

$2-4$

$>4$

Hypoglycemic events

Intensity reported [ $\mathrm{n}=429]$

Mild

Moderate

Severe

Required intervention
Number of patients $(\mathrm{N}=7058)^{\dagger}$

[n=3821]

1999 (28.3)

916 (12.9)

611 (8.6)

253 (3.6)

42 (0.6)

[n=5999]

3061 (51.0)

890 (14.8)

199 (3.3)

$688(11.5)$

$[n=1401]$

$1268(90.5)$

$133(9.5)$

[n=1782]

1175 (65.9)

607 (34.1)

$[n=3705]$

1719 (69.5)

669 (27.0)

3.5)

653 (53.0)

456 (37.1)

122 (9.9)

432 (6.1)

339 (79.0)

85 (19.8)

$3(0.7)$

$2(0.5)$

\section{TABLE 3: Treatment-related observations}

Data shown as $n(\%)$, unless otherwise specified. $\nmid N=7058$, unless otherwise specified. AGI, alpha-glucosidase inhibitor; DPP4i, dipeptidyl peptidase-4 inhibitors; GLP1, glucagon-like peptide-1; SGLT2i, sodium-glucose co-transporter-2 inhibitor; TZD, thiazolidinedione. Others, who were on concomitant non-diabetic medication including antiallergic, anticonvulsant, antidepressant, antiepileptic, antifungal, drugs for erectile dysfunction. The intensity of hypoglycemic events was reported based on the treating physician's clinical judgment. 


\section{Cureus}

The mean $\mathrm{HbA1c}$ levels significantly decreased post-treatment with the glimepiride and metformin with insulin combination with a mean change of 1.33\% (95\% CI, 1.27-1.38; $\mathrm{p}<0.001)$ (Figure 2).

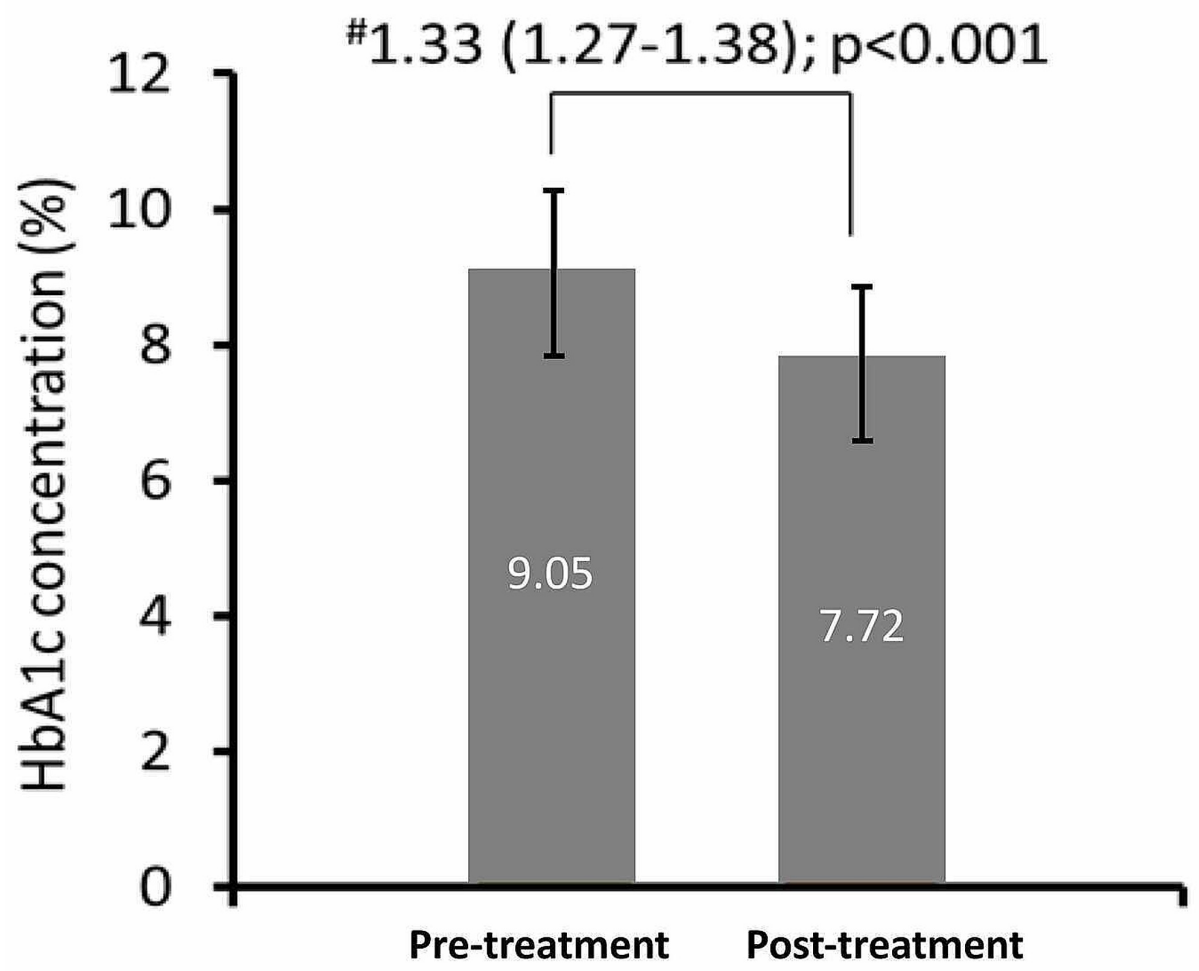

FIGURE 2: Mean change in HbA1c levels from pre-treatment to posttreatment

\#Mean change from pretreatment to posttreatment $(95 \% \mathrm{Cl})$; $\mathrm{p}$-value

HbA1c: glycated hemoglobin

In concomitant anti-diabetic medications, the proportion of patients receiving dipeptidyl peptidase- 4 inhibitors (DPP4i) (28.3\%) was the highest followed by sodium-glucose co-transporter-2 inhibitors (SGLT2i) (12.9\%), alpha-glucosidase inhibitor (AGI) (8.6\%), thiazolidinedione (TZD) (3.6\%), and glucagon-like peptide-1 (GLP1) agonist (0.6\%) (Table 3). The common comorbid conditions included hypertension (64.7\%), dyslipidemia (39.1\%), followed by neuropathy (14.7\%), and coronary artery disease (10.6\%) across the study population (Figure 3) 


\section{Cureus}

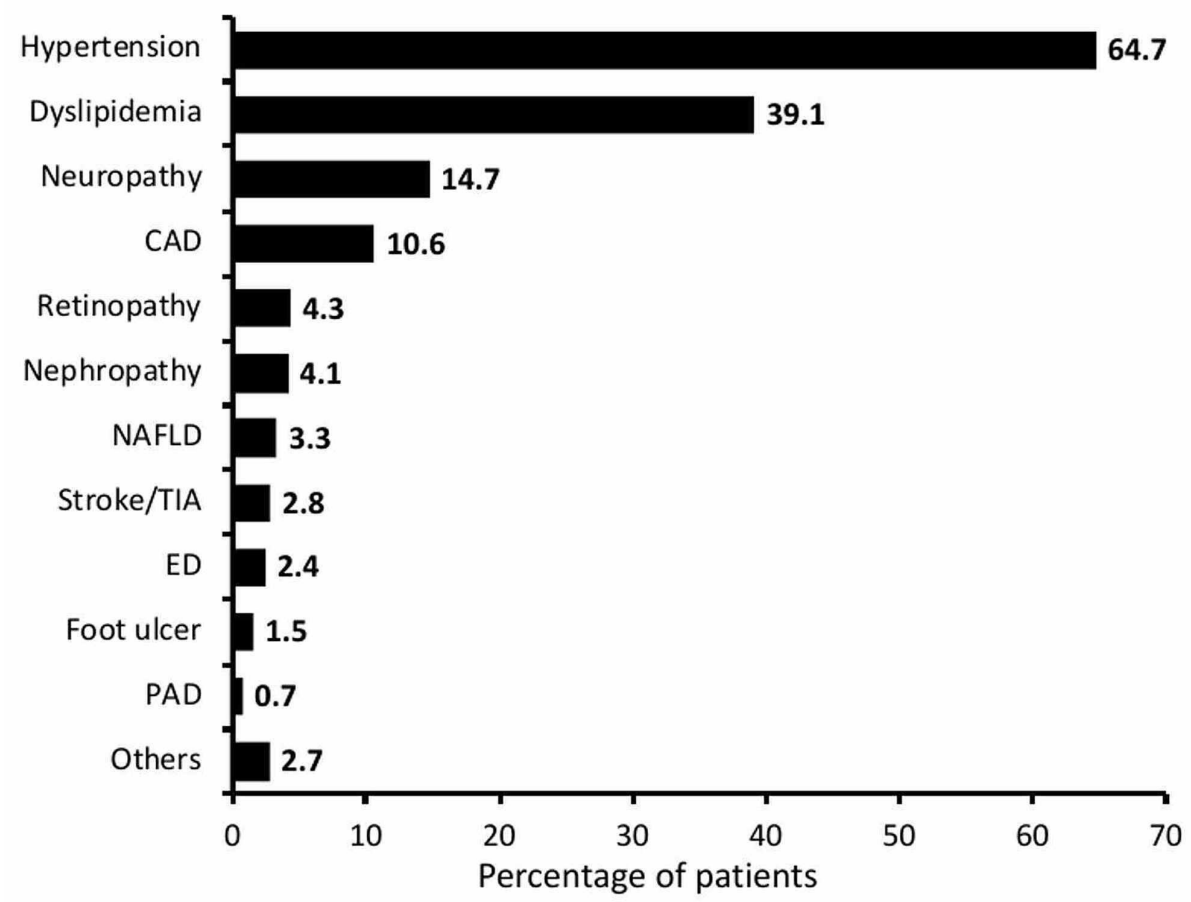

\section{FIGURE 3: Comorbidities associated with T2DM}

T2DM, type 2 diabetes mellitus; CAD, coronary artery disease; ED, erectile dysfunction; NAFLD, non-alcoholic fatty liver disease; PAD, peripheral arterial disease, TIA, transient ischemic attacks

A total of 3705 patients experienced weight changes during the treatment, of which $33.2 \%$ patients showed weight loss and $66.8 \%$ weight gain. The majority of the patients had weight elevation (69.5\%) or reduction (53.0\%) of up to $2 \mathrm{kgs}$. A total of 432 patients reported hypoglycemic events. Among them, $79.0 \%$ of patients had mild and $19.8 \%$ of patients had moderate hypoglycemic events (Table 3). The physician's global evaluation of efficacy and tolerability showed the majority of patients on a good to excellent scale $(97.3 \%$ and 96.6\%) (Figure 4).

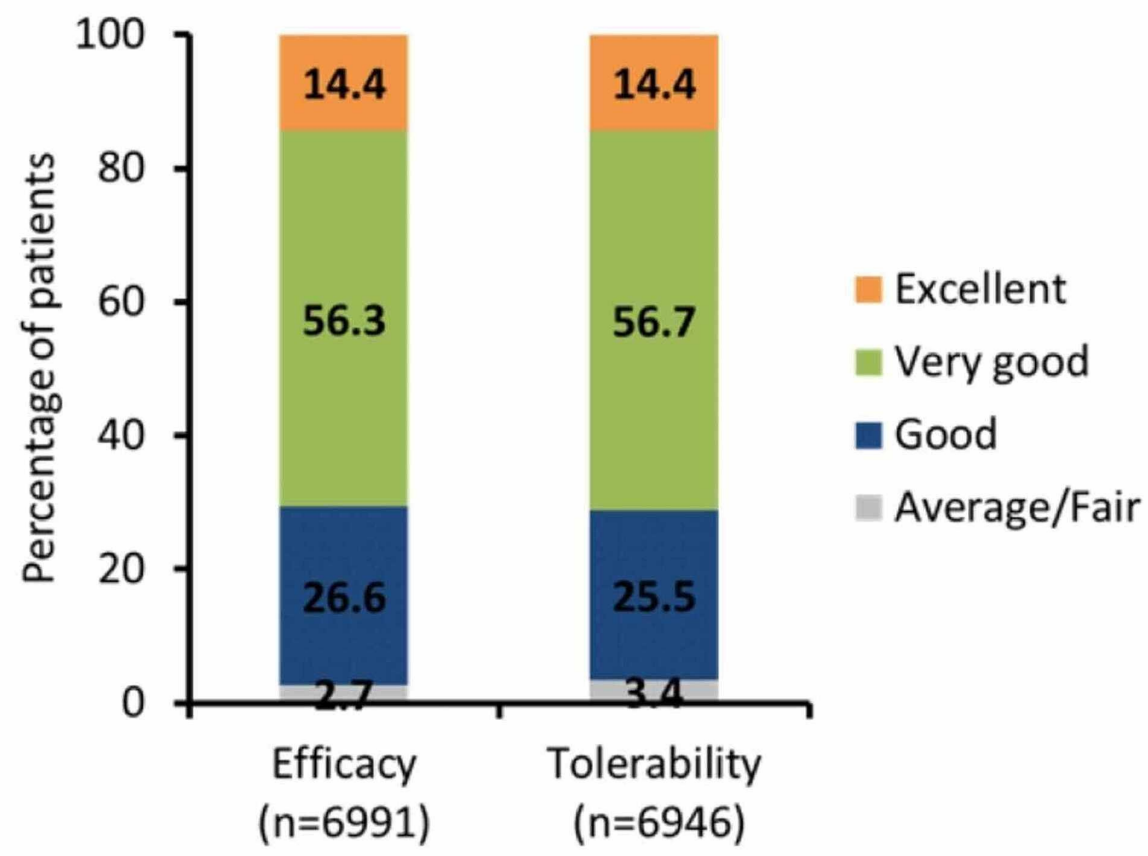

FIGURE 4: Physician global evaluation of efficacy and tolerability of the glimepiride and metformin combination 


\section{Discussion}

T2DM often presents late, and about 70\% of the diagnosed cases from India remain uncontrolled $[17,20]$. Combination therapies involving oral anti-diabetics and insulin have enabled accomplishing a better glycemic index and improve clinical outcomes, resulting in lowering the health complications caused by diabetes. The present study evaluated the use of the glimepiride and metformin combination with insulin to control T2DM in three different age groups: $\geqslant 18-\leqslant 40$ years, $>40-\leqslant 60$ years, and $>60$ years. Moreover, associated conditions and therapies, duration of the therapy, up- and down-titration, glycemic control, hypoglycemic events, and impact on weight were evaluated. This real-life study conducted in outpatient practices will be an important step towards validating the impact of this treatment pattern.

The key findings of this study showed that obesity, sedentary lifestyle, family history, and emotional stress were remarkably higher in patients of age group $>40-\leqslant 60$ years. However, family history was more common in the age group $\geqslant 18-\leqslant 40$ years. Family history for diabetes, sedentary lifestyle, obesity, smoking, and emotional stress increases the chances of acquiring T2DM [21-22]. Family history is an important predictor. The findings of the current study corroborate with the reported study demonstrating a strong association between age, BMI, and smoking with a prevalence of diabetes [23]. Similarly, another study from Africa showed an incidence of hypertension (71\%; 95\% CI 69-73), hyperlipidemia (34\%), and obesity (27\%), along with cataract (32\%), diabetic retinopathy (15\%), impaired renal function (13\%), and erectile dysfunction (in men; 35\%) [24-25]. In the current study, hypertension (64.7\%) and dyslipidemia (39.1\%) were the most common comorbidities observed and managed with antihypertensives and statins, respectively. The observations are in accordance with the reported literature showing the predominance of these comorbidities in India as well as globally.

The mean change in HbA1c levels from pre-treatment to post-treatment with insulin and the glimepiride and metformin combination was significant, indicating good glycemic control.

Reports from the meta-analysis suggest a reduction of $\mathrm{HbA} 1 \mathrm{c}$ with insulin-sulphonylurea combination therapy compared with insulin monotherapy (95\% CI: -1.6 to $-0.5 ; \mathrm{p}<0.01$ ) [26], as well as with placebo (95\% CI: 0.24, 0.69, I 2 = 43.6\%) [27]. A Korean clinical study by Park et al., of a 24 weeks' period, reported a remarkable reduction of $\mathrm{HbA} 1 \mathrm{c}$ with the addition of glimepiride to insulin glargine and metformin as compared to insulin glargine plus metformin (0.49\% [95\% CI: $0.16 \%-0.82 \%], \mathrm{P}=0.005)$ [13]. Another randomized placebo-controlled study conducted in patients with T2DM for more than 10 years duration, who were on metformin and insulin therapy, had glimepiride added, and an effective lowering in HbA1c level with minor hypoglycemic events even after the long duration of T2DM was observed [12]. These studies support the findings from the current study offering an effective therapeutic option for patients not responding to the combination or other drug combinations. Newly diagnosed patients successfully attain glycemic control with monotherapy or a multiple oral drug combination. Nevertheless, over the long term, a strengthened and multidrug regimen becomes a requisite to attain a satisfactory glycemic goal that could be improved by the inclusion of insulin [18].

Dosage up- and down-titration had to be done with the glimepiride and metformin combination as well as insulin to control hyperglycemia, hypoglycemia, and glycemic variability. In one-third of the patients, downtitration of the insulin dose was done, indicating the insulin-sparing effect, with the addition of the glimepiride and metformin combination.

Weight changes are expected in T2DM patients and also due to insulin treatment. Surprisingly, $48 \%$ of patients showed no change in weight. Among the remaining patients, 33.2\% patients showed weight loss while $66.8 \%$ showed weight gain. Glimepiride being modern sulphonylurea has a low propensity to cause weight gain. Metformin use is associated with a decrease in weight if given as a monotherapy or even in combination with insulin or sulfonylurea, which seems to counterbalance the weight gain effect of other anti-diabetic agents [28-29]. In the current study, the sedentary lifestyle observed in all age groups may be one of the contributors associated with weight gain.

Indian clinicians are very accustomed to using the glimepiride and metformin combination along with insulin. Physician global evaluation of efficacy and tolerability showed the majority of patients on a good to excellent scale (97.3\% and $96.6 \%)$.

This was a real-world study depicting the clinical experience with the administration of various strengths of the glimepiride and metformin combination with insulin given in all age groups, including the elderly. Moreover, this combination with insulin was administered to patients with co-morbidities, including hypertension, dyslipidemia, and coronary artery diseases. A high perception of efficacy and tolerability was observed with this combination.

\section{Limitations}

Although this study included a large patient population, it is limited due to its retrospective nature. Besides this, T2DM cases included in this study were enrolled from Indian healthcare centers, which may limit the 
extrapolation of these findings to the general population. The measurement of fasting and postprandial blood glucose levels was not recorded. Additionally, missing data of patients who failed to report has limited the analysis strength of the study parameters.

\section{Conclusions}

The add-on therapy of insulin to the glimepiride and metformin combination and the addition of the glimepiride and metformin combination to insulin therapy will support the successful accomplishment of glycemic control through lowered HbA1c levels. Good to excellent efficacy and tolerability was observed in patients with T2DM across the age groups, early as well as long-standing disease, and those associated with comorbidities like hypertension, dyslipidemia, and coronary artery disease. Hence, this therapy is favorable for the effective management of T2DM.

\section{Additional Information \\ Disclosures}

Human subjects: Consent was obtained or waived by all participants in this study. 1) CLINICOM (Independent Ethics Committee for Evaluation of Protocols for Clinical Research) and 2) ACEAS Independent Ethics Committee issued approval 1) CLINICOM (01573/20.08.2019) and 2) ACEAS (NA). Approvals from the independent ethics committees (IECs) were obtained. The procedure was carried out in accordance with the Declaration of Helsinki and the International Council for Harmonization-Good Clinical Practice (ICH-GCP). As this was a retrospective study where data was collected from medical records consent was waived. Animal subjects: All authors have confirmed that this study did not involve animal subjects or tissue. Conflicts of interest: In compliance with the ICMJE uniform disclosure form, all authors declare the following: Payment/services info: This study was by USV Pvt Ltd. Financial relationships: Dr. Mahesh Abhyankar and Dr. Santosh Revankar declare(s) employment from USV Pvt Ltd. Dr. Mahesh Abhyankar and Dr. Santosh Revankar are employees of USV Pvt Ltd. All other authors have no conflicts of interest to declare. Other relationships: All authors have declared that there are no other relationships or activities that could appear to have influenced the submitted work.

\section{Acknowledgements}

We acknowledge Ms. Farida Hussain, Mr. A Thamburaj, and Ms. Shashikala Borhade, USV Pvt Ltd., for their assistance in carrying out the project. The medical writing support was provided by Dr. Sona Warrior (Scientific Services, USV Pvt Ltd., Mumbai) and Dr. Sapna Patil (Sqarona Medical Communications LLP, Mumbai). We acknowledge Abiogenesis Clinpharm Private Limited for their services in the conduction of the real-world study. Contributors Dr. A C Shyam, Dr. A Jaswanth, Dr. A Kamlesh, Dr. A Lawrence Victor Joe, Dr. A M A Karibasaih, Dr. A M Rao, Dr. A N S Varaprasad, Dr. A Praveen Kumar Reddy, Dr. A Rajeev, Dr. A Ravi Kumar, Dr. A Sethuraman, Dr. A Shanmugam, Dr. A Jayabal, Dr. Abhilash K, Dr. Amaravai Sridhar Reddy, Dr. Ambanna Gowda, Dr. Amrit Nanaiah, Dr. Anand S, Dr. Anantha Padmanavan, Dr. Anil Kumar Reddy I, Dr. Anilkumar A Kustagi, Dr. Aravinda J, Dr. Arun M G, Dr. Arun R, Dr. Arunkumar K B, Dr. Ashok M Kumar, Dr. Ashok Pandappa Yenkanchi, Dr. B A Hanumanthu, Dr. B A Rudrawadi, Dr. B K Sundar, Dr. B Karthik Rao, Dr. B Naveen Babu, Dr. B Prasanna Kumar, Dr. B R K Prakash, Dr. B Rajaganesan, Dr. B Rama Krishna Reddy, Dr. B Ramulu, Dr. B S Sudhir, Dr. B Surender Reddy, Dr. B Suresh Babu, Dr. B.Srinivasulu, Dr. Babu Rajendra Nayak, Dr. Babu Chakravarthy K, Dr. Balasubrahmanyam K, Dr. Basavaraj G Mangshetty, Dr. Bysani Naveen Kumar, Dr. C Jagadeesh, Dr. C Mallikarjun, Dr. C Padmavathi Devi, Dr. C Pradeep, Dr. C H Lakshmi Jagadeesh, Dr. C H Srinivasa Rao, Dr. C H Upendra Shobanadri, Dr. C H Sree Harsha Varma, Dr. Chandramohan P, Dr. Chandrashekar N, Dr. Chikkalingaiah, Dr. D Ganekal Prashanth, Dr. D Mathru, Dr. D Narayan Reddy, Dr. D Venkatesh, Dr. Datta Reddy, Dr. Dhareppa Tammanna Kokatnur, Dr. Dilip Gude, Dr. Dosapati Ramesh, Dr. Durga Prasad Bhimala, Dr. Durga Prasad Nalla, Dr. E A Shahul Hameed, Dr. E M Arunachalam, Dr. E M Surendra, Dr. Eswaran Thangavelu, Dr. G Bal Raju, Dr. G Bhaskara Naidu, Dr. G Jaikumar, Dr. G K Mahesh, Dr. G Kiran, Dr. G Krishnamurthy, Dr. G M Prasad, Dr. G Prakash, Dr. G Raja Gopal, Dr. G Sampavan Kumar, Dr. G Satya Sreenivasa Rao, Dr. G Satyanarayana Raju, Dr. G V Siva Reddy, Dr. Gajendra Mahishale, Dr. Gajjala Rama Krishna Reddy, Dr. Ganesh H K, Dr. Gangaraju V, Dr. Girish Sonwalkar, Dr. Gopala Venkata Giridhar, Dr. Guruprasad Udupi, Dr. Halli Karibasappa, Dr. Harinath Reddy M, Dr. I Arun, Dr. J Giri, Dr. J Kannan, Dr. J Leo Gounalane, Dr. J P Vignesh, Dr. J Senthil Kumar, Dr. J Thiyagarajan, Dr. Jagdish Singh, Dr. Jaidev Sudagani, Dr. Jayalakshmi C, Dr. Jayesh Dhirajlal Shah, Dr. Jayprakash Appajigol, Dr. Joe George, Dr. Joshy Joseph, Dr. K Arumugam, Dr. K Arun Karthik, Dr. K Chandra Obul Reddy, Dr. K D Modi, Dr. K Jayarami Reddy, Dr. K L Udapudi, Dr. K Lavanya, Dr. K M Jeyabalaji, Dr. K Muralidaran, Dr. K Nagesh, Dr. K P Balaraj, Dr. K Ram Vijay Kumar, Dr. K Sarath Chandra Babu, Dr. K Seetharamaiah, Dr. K Subash, Dr. K V Asaithambi, Dr. K Vamsi Krishna, Dr. K Venugopal reddy, Dr. Kailash Pabba, Dr. Kalanitthi A N, Dr. Kalinga B E, Dr. Kalyanraman Kannan, Dr. Kandula Sai, Dr. Kanumuri Srinivas Rao, Dr. Karra Hanumantha Reddy, Dr. Karunesh Kumar H S, Dr. Keerthy Shetty, Dr. Kelli Chinna Babu, Dr. Krishnanunni Polakkulath, Dr. L Srinivasa Murthy, Dr. L Venkatesh, Dr. Lakshmana S Sridhar, Dr. Lakshmi Narayan, Dr. Lalita S Kid, Dr. Laxaman Siddappa Jambagi, Dr. Laxme Gouda, Dr. M Ajay Reddy, Dr. M Bhuvana Priya, Dr. M G Uvaraj, Dr. M Kavitha, Dr. M Leelavathi, Dr. M Malleswara Rao, Dr. M Manju Bhargavi, Dr. M N Ashok, Dr. M Naga Chakravarthy, Dr. M Nagesh Prabhu, Dr. M Prasath, Dr. M R Srinivasa Yogan, Dr. M R Vidhya, Dr. M Ramesh Kumar, Dr. M S Sadhia Ali, Dr. M Sreekanth Reddy, Dr. M Srinivas Rao, Dr. M Suriya Kumar, Dr. M Syed Sulaiman, Dr. M.Ranganath, Dr. Madhav Balkrishna Prabhu, Dr. Madhav 
Pavuluri, Dr. Madhusudan Reddy K, Dr. Mahesh Kumar Marda, Dr. Mala Dharmalingam, Dr. Mallikarjun H, Dr. Manjunath G Anakal, Dr. Manoj Kumar Dash, Dr. Manoj T Koshy, Dr. Margam Kiran Kumar, Dr. Meghanath Yenni, Dr. Metta Madhu, Dr. Mohammad D Shafee, Dr. Mohammed Abubaker, Dr. Mohan G, Dr. Mohd Shaeq Mirza, Dr. N Bhavani, Dr. N Ethiraj, Dr. N Karthikeyan, Dr. N Kotresh, Dr. N Nandagopal, Dr. N Sathyanarayana, Dr. N Srikanth, Dr. Nagaraj S, Dr. Nagarjun B R, Dr. Nagraj Shetty, Dr. Nallamuthuswamy Seenichamy, Dr. Nallaperumal S, Dr. Natarajan Selvaraj, Dr. Naveed Md Syed, Dr. Naveen Angadi, Dr. Nekkanti Narendra Prasad, Dr. Nellaiappan Muthukumarasamy, Dr. Niran Uthaiah, Dr. Nitchenametla Srinivas, Dr. Niteen Chandrakant Shettye, Dr. Nitin B Agrwal, Dr. P Amareswar, Dr. P Hari Kumar Reddy, Dr. P Kamalakannan, Dr. P Mithun Chakravarthy, Dr. P Nitish, Dr. P S Mansur, Dr. P Sateesh Kumar Raju, Dr. P Sreenatha Reddy, Dr. P Subramanyam Reddy, Dr. P V B Sridhar, Dr. P Vishnuram, Dr. Palanivelrajan, Dr. Pantala Chakradhar, Dr. Parakal Haridas Upadhya, Dr. Paramesh S, Dr. Patakamuri Padmalatha, Dr. Paulose Mathayi, Dr. Perumalla Varun Kumar, Dr. Pothamsetty Ravikaladhar Reddy, Dr. Pothiraju Naicker Subbiah, Dr. Prabhurami Reddy, Dr. Pradeep N Shantagiri, Dr. Prahlad Chebbi, Dr. Prasanna Kumar K, Dr. Prasanth Sankar, Dr. Prasun Deb, Dr. Praveen Kusubi, Dr. Praveen M, Dr. Praveen Ramchandra, Dr. Pruthvi B C, Dr. Purna G A Sreeramaneni, Dr. R Arul Prakash, Dr. R Kumaresan, Dr. R N Bhat, Dr. R N Mehrotra, Dr. R Niresh Kannan, Dr. R Prabakar, Dr. R Santosh, Dr. R Shashi Kumar, Dr. R Srinivasan, Dr. R Umarani, Dr. R V N Umamaheswara Rao, Dr. R Thirumurugan, Dr. Rachamallu Ravichandra Reddy, Dr. Raghavendra Prakash, Dr. Raghurama N K, Dr. Rahul P G, Dr. Raj Mohan L, Dr. Rajeev H, Dr. Rajeev Joshi, Dr. Rajendra M Arya, Dr. Rajendran V, Dr. Rajesh K, Dr. Rajesh Regonda, Dr. Rajesh Seth, Dr. Rajesh Subhash Talathi, Dr. Rakesh Sahay, Dr. Raman Boddula, Dr. Ramesh M Dodabhangi, Dr. Ranjith A Shetty, Dr. Ravi G R, Dr. Ravi Kumar, Dr. Ravi Sreenivas, Dr. Renuka Sriram, Dr. Robin George, Dr. S G Harish, Dr. S G Moazam, Dr. S Kesava Rao, Dr. S N Ganesha Moorthy, Dr. S Naga Narasimhaiah, Dr. S P Sathish Kumar, Dr. S Ramanathan, Dr. S Sathyanarayana Murthy, Dr. S Selvamuthukumaran, Dr. S Shyam Sundar Reddy, Dr. S Suneetha, Dr. S Suthakaran, Dr. S Nandha Kumar, Dr. Sabeer T K, Dr. Sabesan Swaminathan, Dr. Sadashivappa Chandrashekar, Dr. Sai Pradeep, Dr. Sajith V S, Dr. Sandeep Sudhakar, Dr. Sanjeev Rao Girimaji, Dr. Sanjoy Paul, Dr. Sankara B V, Dr. Satish B Kinagi, Dr. Satish Patil, Dr. Sdm Sekhar, Dr. Sepuri Krishna Mohan, Dr. Shaik Ahmed, Dr. Shakeel Ahamed, Dr. Shankar V, Dr. Shivanand Boodihal, Dr. Shridhar Balavanth Kulkarni, Dr. Siddanna D Kamat, Dr. Siripurapu Kiran Kumar, Dr. Stanley Ambroise, Dr. Subhash Chandra Jayaram Balleke, Dr. Subramani I, Dr. Sudha Sathian, Dr. Sudhir Revansiddappa Jambagi, Dr. Sunil Kumar, Dr. Sunil N Gayad, Dr. Sunkara Satya Murthy, Dr. Surekha B Shetty, Dr. T M Venkateswara Rao, Dr. T R Sivagnanam, Dr. T S Ramaswamy, Dr. T Munusamy, Dr. Thummalcheral Dhanraju, Dr. Tirthankar, Dr. U Rajanikanth, Dr. V Dineshkumar, Dr. V G Subramanian, Dr. V Mahadevan, Dr. V N Selvam, Dr. V Rajendran, Dr. V Ravindranath, Dr. V Sathiyamoorthy, Dr. V Sreekanth Reddy, Dr. V Venkata Rama Kumar, Dr. V Vigneswaran, Dr. Valluri Srinivas Reddy, Dr. Veera Reddy P, Dr. Vidhya Thambirajah, Dr. Vijay S Desai, Dr. Vijayakumar P, Dr. Vijaykumar K Chaini, Dr. Vijith Kumar K, Dr. Vikas Patil, Dr. Vikrant B Ghatnatti, Dr. Vinay M Dipali, Dr. Vinay Swamy, Dr. Vinu Abraham, Dr. Viswanathan A, Dr. Y S Ravi Kumar, Dr. Yalamanchi Sadasiva Rao, Dr. Yarrathota Balaji. Authorship All named authors take responsibility for the integrity of the work as a whole and have given their approval for this version to be published. The contents published herein represents the views and does not necessarily represent the views or opinions of USV Pvt Ltd. and/or its affiliates. The details published herein are intended for the discrimination of educational, academic, and/or research purposes and are not intended as a substitute for professional medical advice, diagnostics, or treatment.

\section{References}

1. International Diabetes Federation (IDF). Diabetes Atlas 9th edition . (2019). https://www.diabetesatlas.org/en/sections/worldwide-toll-of-diabetes.html.

2. Li CJ, Zhang JY, Yu DM, Zhang QM: Adding glimepiride to current insulin therapy increases high-molecular weight adiponectin levels to improve glycemic control in poorly controlled type 2 diabetes. Diabetol Metab Syndr. 2014, 6:41. 10.1186/1758-5996-6-41

3. Charpentier G, Fleury F, Kabir M, Vaur L, Halimi S: Improved glycaemic control by addition of glimepiride to metformin monotherapy in type 2 diabetic patients. Diabet Med. 2001, 18:828-834. 10.1046/j.14645491.2001.00582.x

4. Arya DS, Chowdhury S, Chawla R, et al.: Clinical benefits of fixed dose combinations translated to improved patient compliance. J Assoc Physicians India. 2019, 67:58-64.

5. American Diabetes Association: Pharmacologic approaches to glycemic treatment: standards of medical care in diabetes-2019. Diabetes Care. 2019, 42:90-102. 10.2337/dc19-S009

6. American Diabetes Association: Glycemic targets: standards of medical care in diabetes-2018. Diabetes Care. 2018, 41:55-64. 10.2337/dc18-S006

7. Kalra S, Deb P, Gangopadhyay KK, Gupta S, Ahluwalia A: Capacity and confidence building for general practitioners on optimum insulin use. J Family Med Prim Care. 2019, 8:3096-3107. 10.4103/jfmpc.jfmpc_635_19

8. Feinglos MN, Thacker CR, Lobaugh B, DeAtkine DD, McNeill DB, English JS, Bursey DL: Combination insulin and sulfonylurea therapy in insulin-requiring type 2 diabetes mellitus. Diabetes Res Clin Pract. 1998, 39:193-199. 10.1016/s0168-8227(98)00003-5

9. Aviles-Santa L, Sinding J, Raskin P: Effects of metformin in patients with poorly controlled, insulin-treated type 2 diabetes mellitus. A randomized, double-blind, placebo-controlled trial. Ann Intern Med. 1999, 131:182-188. 10.7326/0003-4819-131-3-199908030-00004

10. Yki-Jarvinen H, Ryysy L, Nikkila K, Tulokas T, Vanamo R, Heikkilä M: Comparison of bedtime insulin regimens in patients with type 2 diabetes mellitus. A randomized, controlled trial. Ann Intern Med. 1999, 130:389-396. 10.7326/0003-4819-130-5-199903020-00002

11. Wulffelé MG, Kooy A, Lehert P, et al.: Combination of insulin and metformin in the treatment of type 2 
diabetes. Diabetes Care. 2002, 25:2133-2140. 10.2337/diacare.25.12.2133

12. Nyback-Nakell A, Adamson U, Lins PE, Hallin LL: Adding glimepiride to insulin + metformin in type 2 diabetes of more than 10 years' duration-a randomized, double-blind, placebo-controlled, cross-over study. Diabetes Res Clin Pract. 2014, 103:286-291. 10.1016/j.diabres.2013.12.062

13. Park CY, Kang JG, Chon S, Noh J, Oh SJ, Lee CB, Park SW: Comparison between the therapeutic effect of metformin, glimepiride and their combination as an add-on treatment to insulin glargine in uncontrolled patients with type 2 diabetes. PloS One. 2014, 9:87799. 10.1371/journal.pone.0087799

14. American Diabetes Association: Implications of the United Kingdom Prospective Diabetes Study . Diabetes Care. 2002, 25:28-32. 10.2337/diacare.25.2007.S28

15. Unnikrishnan IR, Anjana RM, Mohan V: Importance of controlling diabetes early-the concept of metabolic memory, legacy effect and the case for early insulinisation. J Assoc Phys Indian. 2011, 59:8-12.

16. Unnikrishnan AG, Pandit K, George J, Venkataraman S, Abhyankar MV: Clinical utilization pattern of multiple strengths of glimepiride and metformin fixed dose combinations in Indian type 2 diabetes patients. J Assoc Physicians India. 2020, 68:57-61.

17. Bajaj S, Das AK, Kalra S, et al.: BE-SMART (basal early strategies to maximize HbA1c reduction with oral therapy): expert opinion. Diabetes Ther. 2019, 10:1189-1204. 10.1007/s13300-019-0629-z

18. Kuritzky L: Addition of basal insulin to oral antidiabetic agents: a goal-directed approach to type 2 diabetes therapy. MedGenMed. 2006, 8:34.

19. Efficacy of glimepiride as an add-on therapy to insulin in patients with high insulin requirement . (2017). https:/www.morressier.com/article/efficacy-glimepiride-addon-therapy-insulin-patients-high-insulinrequirement $/ 59 \mathrm{~d} 51 \ldots$.

20. Kanungo S, Mahapatra T, Bhowmik K, Mahapatra S, Saha J, Pal D, Sarkar K: Diabetes scenario in a backward rural district population of India and need for restructuring of health care delivery services. Epidemiol. 2016, 6:1. 10.4172/2161-1165.1000224

21. Asiimwe D, Mauti GO, Kiconco R: Prevalence and risk factors associated with type 2 diabetes in elderly patients aged 45-80 years at Kanungu District. J Diabetes Res. 2020, 2020:5152146. 10.1155/2020/5152146

22. Bellou V, Belbasis L, Tzoulaki I, Evangelou E: Risk factors for type 2 diabetes mellitus: an exposure-wide umbrella review of meta-analyses. PloS One. 2018, 13:0194127. 10.1371/journal.pone.0194127

23. Boffetta P, McLerran D, Chen Y, et al.: Body mass index and diabetes in Asia: a cross-sectional pooled analysis of 900,000 individuals in the Asia cohort consortium. PloS One. 2011, 6:19930. 10.1371/journal.pone.0019930

24. Ekoru K, Doumatey A, Bentley AR, et al.: Type 2 diabetes complications and comorbidity in Sub-Saharan Africans. E Clinical Medicine. 2019, 16:30-41. 10.1016/j.eclinm.2019.09.001

25. Nowakowska M, Zghebi SS, Ashcroft DM, et al.: The comorbidity burden of type 2 diabetes mellitus: patterns, clusters and predictions from a large English primary care cohort. BMC Med. 2020, 18:145. 10.1186/s12916-019-1373-y

26. Vos RC, van Avendonk MJ, Jansen H, et al.: Insulin monotherapy compared with the addition of oral glucose lowering agents to insulin for people with type 2 diabetes already on insulin therapy and inadequate glycaemic control. Cochrane Database Syst Rev. 2016, 9:CD006992. 10.1002/14651858.CD006992.pub2

27. Hirst JA, Farmer AJ, Dyar A, Lung TW, Stevens RJ: Estimating the effect of sulfonylurea on HbA1c in diabetes: a systematic review and meta analysis. Diabetologia. 2013, 56:973-984. 10.1007/s00125-013-28566

28. Hermansen K, Mortensen LS: Bodyweight changes associated with antihyperglycaemic agents in type 2 diabetes mellitus. Drug Safe. 2007, 30:1127-1142. 10.2165/00002018-200730120-00005

29. Schernthaner G, Matthews DR, Charbonnel B, Hanefeld M, Brunetti P: Efficacy and safety of pioglitazone versus metformin in patients with Type 2 diabetes mellitus: a double-blind, randomized trial. J Clin Endocrinol Metab. 2004, 89:6068-6076. 10.1210/jc.2003-030861 